\title{
Composite Membrane Based on Graphene Oxide Sheets and Nafion for Polymer Electrolyte Membrane Fuel Cells
}

\author{
Liang Wang, ${ }^{\text {a, }, \text {, }}$ Junmo Kang, ${ }^{\mathrm{b}}$ Jae-Do Nam, ${ }^{\mathrm{c}, \mathrm{d}}$ Jonghwan Suhr,,${ }^{\text {,d }}$ Ajay K. Prasad, \\ and Suresh G. Advani ${ }^{\mathrm{a}}$ \\ ${ }^{a}$ Center for Fuel Cell Research, Department of Mechanical Engineering, University of Delaware, Newark, \\ Delaware 19716-3140, USA \\ ${ }^{b}$ Department of Materials Science and Engineering, Northwestern University, Evanston, Illinois 60208, USA \\ ${ }^{c}$ Department of Polymer Science and Engineering, Sungkyunkwan University, Suwon 440-746, Korea \\ ${ }^{d}$ Department of Energy Science, Sungkyunkwan University, Suwon 440-746, Korea
}

\begin{abstract}
A composite membrane for fuel cell applications was prepared by incorporating custom-made graphene oxide (GO) in Nafion resin. The GO was used to provide mechanical reinforcement to Nafion. Transmission electron microscopy confirmed the formation of highly crystalline and individually-dispersed graphene oxide sheets. Tensile strength, water uptake, swelling, proton conductivity and electrical conductivity of the composite membranes were measured and compared with pure Nafion. The polarization curves indicated that the fuel cell performance of the $3 \mathrm{wt} \% \mathrm{GO} / \mathrm{Nafion}$ composite membrane was similar to that of the pure Nafion membrane, but the composite membrane was superior to Nafion in terms of mechanical properties.

(C) The Author(s) 2014. Published by ECS. This is an open access article distributed under the terms of the Creative Commons Attribution 4.0 License (CC BY, http://creativecommons.org/licenses/by/4.0/), which permits unrestricted reuse of the work in any medium, provided the original work is properly cited. [DOI: 10.1149/2.0021501eel] All rights reserved.
\end{abstract}

Manuscript submitted August 18, 2014; revised manuscript received October 13, 2014. Published October 29, 2014.

Fuel cells are an important enabling technology for the nation's energy portfolio and have the potential to revolutionize power generation by offering a cleaner, more-efficient alternative to the combustion of gasoline and other fossil fuels. Fuel cells have already demonstrated their potential to replace the internal-combustion engine in vehicles, and provide power in stationary and portable power applications because they are energy-efficient, clean, and fuel-flexible. ${ }^{1}$ The proton exchange membranes (PEMs) currently used in fuel cells, such as Nafion membranes, exhibit high proton conductivity, and good chemical and physical stability at moderate temperatures.

During normal operation of a fuel cell, the membrane electrode assembly (MEA) is subjected to compressive stress between the bipolar plates which can lead to time-dependent deformation (i.e. creep) of the polymer electrolyte membrane. Polymer creep can cause permanent membrane thinning and eventual mechanical failure (pinhole formation, for example) especially when compounded by chemical or other physical degradation mechanisms. ${ }^{2}$ Tough, durable membranes improve fuel cell longevity, as repeated changes in temperature and membrane water content during operational cycling can cause stress-buildup and membrane failure in areas of concentrated stress. ${ }^{3,4}$ Therefore, the mechanical property of PEMs is recognized as a key requirement to improve the durability of PEMFCs. ${ }^{5}$

In order to achieve better fuel cell durability, the mechanical properties of membranes such as Nafion still need to be improved. Reinforced composite membranes for PEMFCs have been reported earlier, where the reinforcement is provided by a porous polytetrafluoroethylene (PTFE) mesh, carbon nanotubes, or carbon fibers. The presence of porous PTFE in the composite membrane decreases its proton conductivity. ${ }^{6}$ Carbon nanotubes (CNTs) have attracted particular attention for their unique structural, mechanical, and electrical properties, with extensive applications in many fields. ${ }^{7,8}$ Studies using MWCNTs in polymer-composites reported an increased storage modulus. ${ }^{9}$ While MWCNTs can also be used to mechanically reinforce the membrane, the addition of MWCNTs may cause the formation of an electron transport pathway across the membrane's thickness which is detrimental to fuel cell performance.

Graphene oxides have demonstrated their usefulness in several important applications as an amphiphilic soft material with strong interfacial interactions oxygen-containing functional groups, large surface area, intrinsically excellent physical properties, and chemical tunability of properties. ${ }^{10-12}$ They have been studied for fuel cell applications as an additive to proton exchange membranes by several

\footnotetext{
*Electrochemical Society Active Member.
}

${ }^{z}$ E-mail: lwangx@udel.edu groups since 2012. Choi et al. prepared GO/Nafion membranes for DMFC applications and found that the transport properties of Nafion are favorably modified by the incorporation of GO, which greatly enhanced fuel cell performance. ${ }^{13}$ Functionalized graphene oxides have also been explored to improve water retention of fuel cell membranes. Enotiadis et al. studied GO/Nafion membranes with graphene oxides carrying various hydrophilic functional groups $\left(-\mathrm{NH}_{2},-\mathrm{OH}\right.$, $\left.-\mathrm{SO}_{3} \mathrm{H}\right)$ and found that the organically functionalized $\mathrm{GO}$ can improve proton transport and water retention of Nafion. ${ }^{14}$ However, the electrical conductivity of GO/Nafion membranes has not been studied to date.

In this work, we investigated the use of graphene oxide to provide mechanical reinforcement to the Nafion membrane. Unlike carbon nanotubes (CNTs), the low electrical conductivity of GO is expected to preserve the electrical resistance of the composite membrane. The loading of GO in Nafion was optimized based on the membrane's mechanical properties and fuel cell performance.

\section{Experimental}

GO was prepared from natural graphite flakes (Alfa Aesar, 99.8\%) according to a modified Hummers method. ${ }^{15,16}$ A flask containing $\mathrm{H}_{2} \mathrm{SO}_{4}(46 \mathrm{~mL})$ was cooled in an ice bath and graphite $(0.6 \mathrm{~g})$ and $\mathrm{NaNO}_{3}(1 \mathrm{~g})$ were added. After homogeneous dispersion of the graphite flakes in the mixing solution, $\mathrm{KMnO}_{4}(3 \mathrm{~g})$ was slowly added to the flask to avoid rapid chemical reaction and to prevent the temperature from exceeding $10^{\circ} \mathrm{C}$. To individually disperse the GO sheets with high amounts of oxygen functional groups, the reaction mixture in the flask was stirred for 6 days at $35^{\circ} \mathrm{C}$ forming a yellow $\mathrm{GO}$ solution. Next, deionized (DI) water $(80 \mathrm{~mL})$ was added and stirred for $30 \mathrm{~min}$. The reaction mixture was then diluted to $200 \mathrm{~mL}$ by adding more DI water with $6 \mathrm{~mL}$ of $\mathrm{H}_{2} \mathrm{O}_{2}$. To remove the remaining metals in the reaction solution, $250 \mathrm{~mL}$ of $10 \% \mathrm{HCl}$ was added and stirred for $1 \mathrm{~h}$. Finally, the reaction mixture was washed repeatedly with DI water until it reached $\mathrm{pH} \mathrm{7,} \mathrm{and} \mathrm{the} \mathrm{filtered} \mathrm{solids} \mathrm{were} \mathrm{dried} \mathrm{under}$ vacuum for 1 day at room temperature.

Five percent Nafion solution (E.I. DuPont) was dried at $60^{\circ} \mathrm{C}$ to vaporize the solvent. The Nafion resin was then dissolved in dimethylacetamide (DMAC) to form Nafion/DMAC solution. Next, the prepared GO was added to the Nafion/DMAC solution. The loading of GO was controlled at $2.3,3$, and $5 \mathrm{wt} \%$ based on the weight of the entire membrane. An excess amount of $\mathrm{NaOH}$ was added to the mixture to neutralize all the sulfonic acid groups in Nafion to the sodium salt form. The mixture was sonicated for at least 2 hours to uniformly disperse the GO in Nafion. Then the GO/Nafion/DMAC solution was 
poured over a glass plate. The glass plate was heated on leveled hotplate at $80^{\circ} \mathrm{C}$ for $4 \mathrm{~h}$, and then in a vacuum oven at $150^{\circ} \mathrm{C}$ for $2 \mathrm{~h}$. The prepared composite membrane was then immersed in $0.5 \mathrm{M}$ sulfuric acid for 2 hours, and then rinsed with DI water. The thickness of the prepared GO/Nafion membrane was around $30 \mu \mathrm{m}$.

Finally, the composite membrane was dried and hot-pressed between catalyst-coated gas diffusion media (CCDM) with $0.4 \mathrm{mg} / \mathrm{cm}^{2}$ $\mathrm{Pt}$ loading at $130^{\circ} \mathrm{C}$ for 2 mins to fabricate the MEA. Baseline MEAs were prepared similarly using pure Nafion membranes. The MEAs were assembled in a $10 \mathrm{~cm}^{2}$ fuel cell and a polarization curve was obtained for each type of membrane using the Arbin fuel cell test stand. The results of the baseline pure Nafion membrane were compared with the composite GO/Nafion membranes.

Samples of the membrane were dried in a vacuum oven at $80^{\circ} \mathrm{C}$ for $12 \mathrm{~h}$. The tensile strength of the recast Nafion and GO/Nafion membranes was measured in accordance with ASTM Standards. ${ }^{17}$ Thirteen mm cardboard end tabs were bonded to the ends of $51 \mathrm{~mm}$ $\times 6.4 \mathrm{~mm}$ membrane samples and thickness measurements were taken at three locations along the gage length of the specimen. The specimens were tested to failure in an Instron Model 5848 Micro Tester at a strain rate of $20 \mathrm{~mm} / \mathrm{mm}$-min. The tensile strength was calculated from the maximum load and the average thickness of each specimen at $23^{\circ} \mathrm{C}$ and $50 \%$ relative humidity. Five replicates of each sample were tested, and the average and standard deviation were calculated accordingly.

Recast Nafion and GO/Nafion membrane samples were weighed after immersing them in deionized water at $60^{\circ} \mathrm{C}$ for $8 \mathrm{~h}$. The samples were then dried in a vacuum oven at $80^{\circ} \mathrm{C}$ for $12 \mathrm{~h}$ and weighed again. Water content $(\Delta W)$ was calculated as

$$
\Delta W(\text { wt. } \%)=\left(W_{2}-W_{1}\right) / W_{1} \times 100
$$

where $W_{1}$ and $W_{2}$ are the dry and wet masses of the sample, respectively.

Membrane specimens with a size $40 \mathrm{~mm} \times 50 \mathrm{~mm}$ were dried in the vacuum oven at $80^{\circ} \mathrm{C}$ for $12 \mathrm{~h}$ and the distance between two specified positions was measured $\left(L_{1}\right)$. The measurement was repeated after the samples were soaked in deionized water at $60^{\circ} \mathrm{C}$ for $8 \mathrm{~h}\left(L_{2}\right)$. The dimensional change $(\Delta L)$ was calculated as follows

$$
\Delta L(\%)=\left(L_{2}-L_{1}\right) / L_{1} \times 100
$$

Five samples were tested for each membrane. The average value was calculated based on the results from five samples.

The polarization I-V evaluation of the fuel cell was conducted and controlled by a fuel cell test station from Arbin Instruments. The $\mathrm{H}_{2}$ and $\mathrm{O}_{2}$ pipeline temperatures were maintained $5^{\circ} \mathrm{C}$ higher than the saturators to prevent water condensation in the feed lines. Hydrogen fuel and oxygen were fed in co-flow to the fuel cell. The fuel cell tests were conducted at ambient pressure. The fuel cell was conditioned for $8 \mathrm{~h}$ at a current density of $1 \mathrm{~A} / \mathrm{cm}^{2}$ with fully humidified $\mathrm{H}_{2} / \mathrm{O}_{2}$ at stoichiometries of 1.5/2. Data were recorded after stable performance was obtained at $100 \%$ relative humidity. For each membrane, at least two samples were tested for confirming the repeatability.

Electronic conductivity was measured using $30 \mathrm{~mm} \times 10 \mathrm{~mm}$ membrane specimens that were dried at $120^{\circ} \mathrm{C}$ in an oven for 12 hours. The specimens were then laid flat on a glass plate and the in-plane electrical conductivity was measured using four copper probes. The probes were $10.9 \mathrm{~mm}$ wide and spaced $11.9 \mathrm{~mm}$ apart. A $400 \mathrm{~g}$ mass was placed on top of the probes to ensure proper contact with the membrane sample. Four-probe DC conductivity measurements were collected using a Keithley 2601A Sourcemeter with a constant voltage of $100 \mathrm{mV}$.

To measure proton conductivity, $30 \mathrm{~mm} \times 10 \mathrm{~mm}$ membrane specimens were soaked in DI water at room temperature for 12 hours. Two-probe electrochemical impedance spectroscopy (EIS) measurements were carried out using a VersaSTAT 3 potentiostat (Princeton Applied Research) with VersaStudio data acquisition software in the frequency range of $1 \mathrm{MHz}$ to $0.1 \mathrm{~Hz}$. Impedance data were fit to a typical Randle's circuit using ZView plotting software (Scribner Associates). The $\mathrm{x}$-intercept of the impedance plots was taken to be the ionic resistance of the electrolyte. For both types of measurements, the in-plane conductivity was calculated as:

$$
\sigma=\frac{L}{R W t}
$$

where $L$ is the distance between the probes, $R$ is the electronic or ionic resistance, $W$ is the width of the probes, and $t$ is the thickness of the membrane. Three replicates of each sample were tested. The average value of all samples was used for comparison.

\section{Results and Discussion}

The degree of oxidation in the GO sheet was estimated by X-ray photoelectron spectroscopy (XPS). The XPS curves of GO sheets with reaction times of 1 and 6 days showed no significant difference in the $\mathrm{C} 1 \mathrm{~s}$ and $\mathrm{O} 1 \mathrm{~s}$ peaks, as shown in Fig. 1a. However, the C-O/C-C peak ratio of GO with a reaction time of 6 days was dramatically enhanced up to 1.65 , which is much higher than 1.12 for GO after 1 day (Fig. 1b). This result clearly shows the formation of high amounts of oxygen functional groups over the surface of the GO sheet after 6 days. In particular, the peak corresponding to the carboncarbon bond $(284.6 \mathrm{eV})$ was significantly decreased after reacting for 6 days. This indicates that a long reaction time enhances the formation of $\mathrm{sp}^{3}$ bonds and gives rise to an energy gap in the electron density of states, resulting in non-conducting GO sheets. ${ }^{18}$
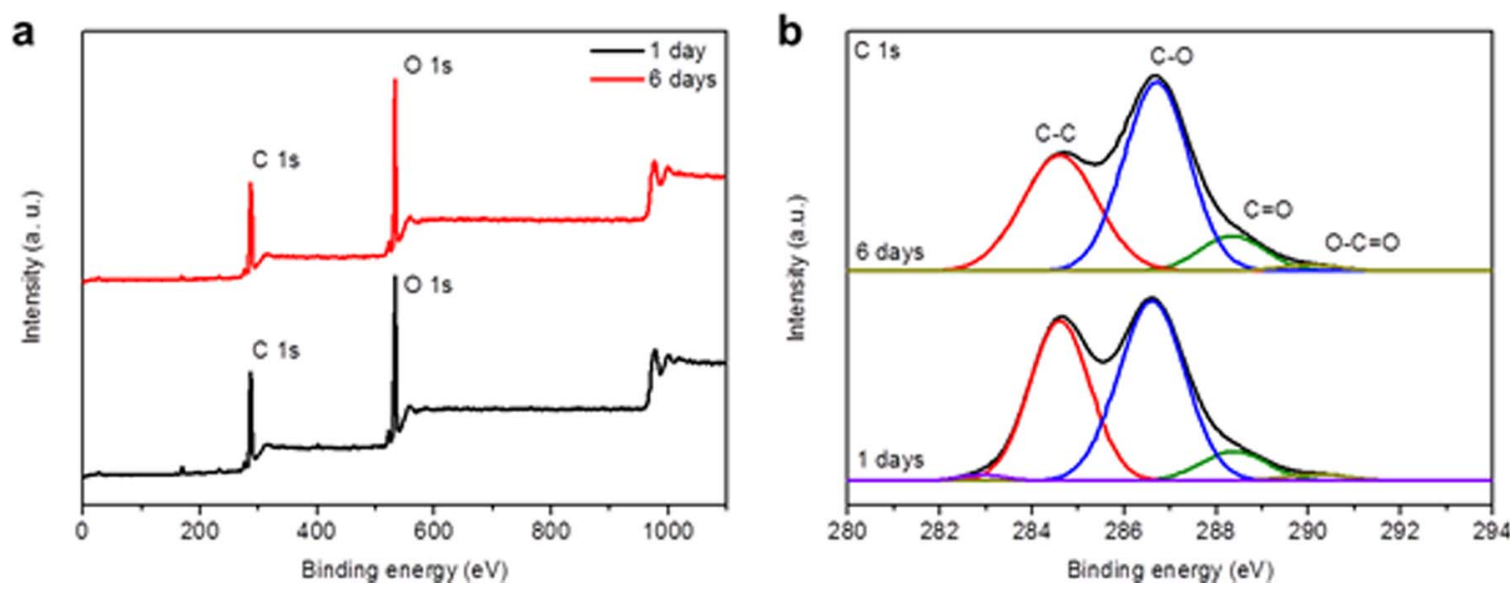

Figure 1. XPS spectra of GO sheets with 1 and 6 days reaction time: (a) XPS wide-scan spectra, and (b) high-resolution spectra for C 1s. 


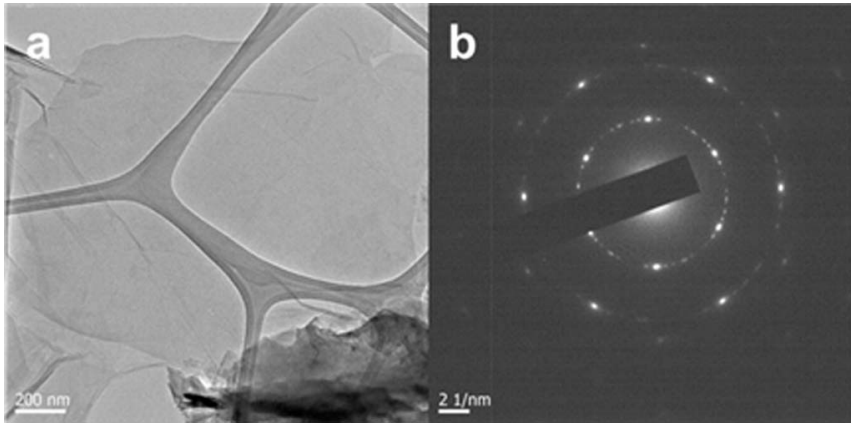

Figure 2. (a) TEM image of GO sheet with wrinkles, (b) SAED patterns of GO sheet.

We characterized the size and crystalline structures of GO sheets using transmission electron microscopy (TEM, JEOL, JEM 2100) operated at $200 \mathrm{kV}$. As shown in Fig. 2a, GO has a large size $\left(\sim 1 \mu \mathrm{m}^{2}\right)$ with wrinkles over its surface visible as dark lines. To investigate the crystalline quality of the GO, we obtained the selected area electron diffraction (SAED) pattern. Fig. 2b shows multiple hexagonal rings with different spot sizes, revealing the presence of domain boundaries in the selected region and the multiple-layer structure of GO sheets. ${ }^{19}$ From an analysis of the SAED pattern, we confirmed that the highly crystalline GO sheets were individually dispersed.

Tensile test results (Fig. 3) showed that the tensile strength of the GO/Nafion membranes was significantly improved compared to that of the pure recast Nafion membrane. For pure recast Nafion membranes, a tensile strength of $12.2 \mathrm{MPa}$ (average value from five specimens) was recorded. In contrast, the tensile strength of the $3 \mathrm{wt} \%$ GO/Nafion membrane was over 30\% higher than the pure Nafion membrane. This increase in tensile strength can be attributed to mechanical reinforcement by the inclusion of GO. The mechanical reinforcement provided by the graphene oxides makes it possible to reduce the thickness of the composite membrane without compromising its tensile strength, such that the fuel cell performance of the membrane can be further improved.

Water uptake and swelling of recast Nafion and GO/Nafion membranes were obtained at $60^{\circ} \mathrm{C}$ as shown in Fig. 4. The reduced water uptake of GO/Nafion membranes was due to the restricted dimensional change of the membrane by GO reinforcement. The dimensional stability of the GO/Nafion membranes, before and after absorbing water, was also improved due to GO reinforcement.

As shown in Fig. 5, the fuel cells were tested at $70^{\circ} \mathrm{C}$ and $100 \%$ relative humidity by supplying it with $\mathrm{H}_{2} / \mathrm{O}_{2}$ at stoichiometries of

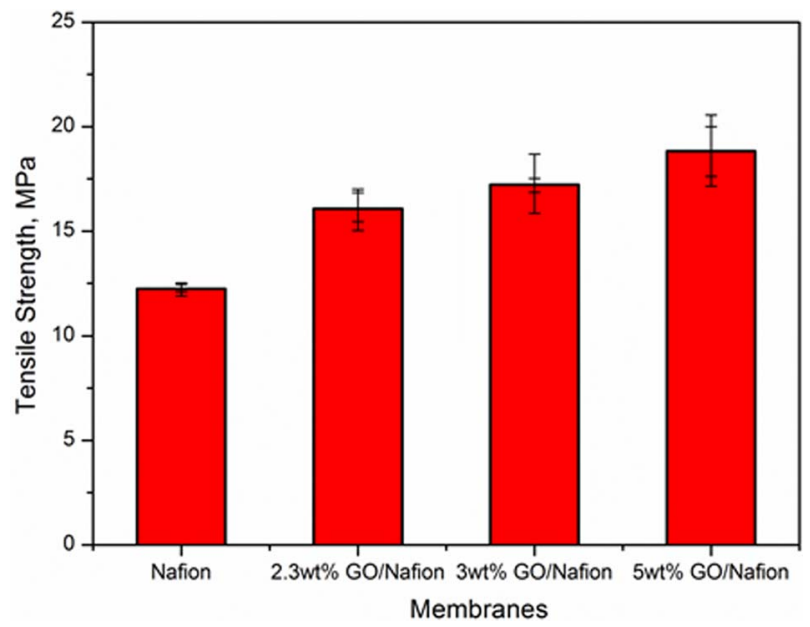

Figure 3. Tensile strength of recast Nafion and GO/Nafion membranes.

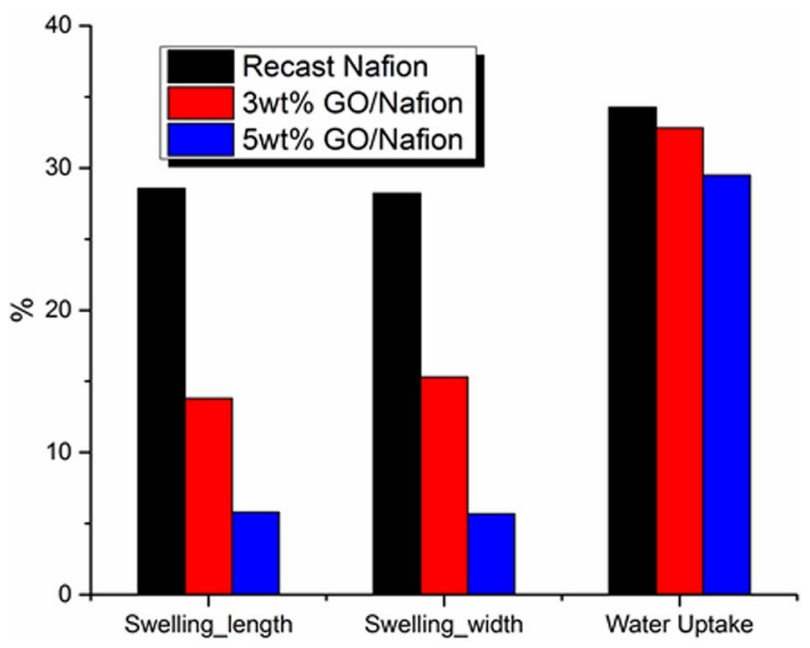

Figure 4. Swelling and water uptake of recast Nafion and GO/Nafion membranes.

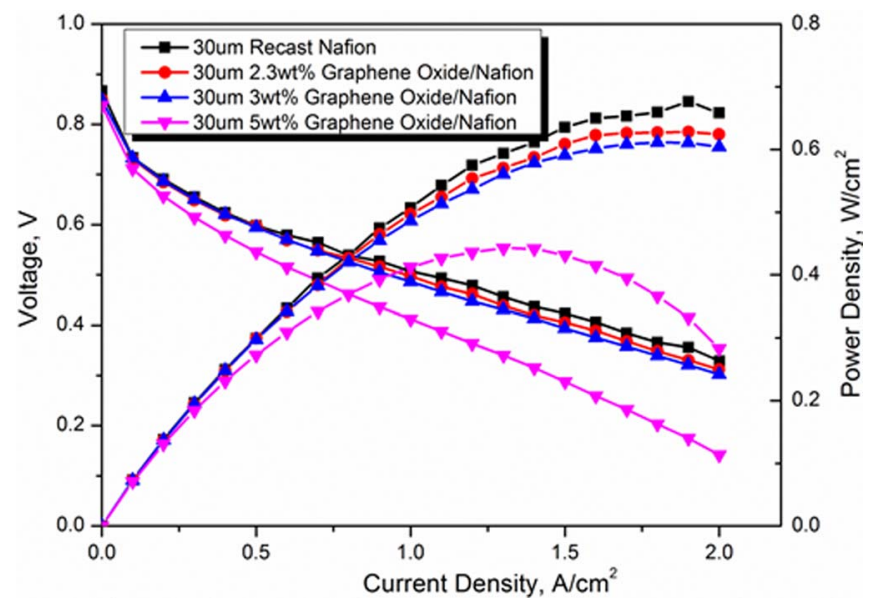

Figure 5. Fuel cell performance of recast Nafion, $2.3 \mathrm{wt} \%$ GO/Nafion, $3 \mathrm{wt} \%$ $\mathrm{GO} / \mathrm{Nafion}$ and $5 \mathrm{wt} \% \mathrm{GO} / \mathrm{Nafion}$ membranes at $70^{\circ} \mathrm{C}$ with $100 \% \mathrm{RH}$.

$1.5 / 2$. The polarization curves clearly show that the performance of the 2.3 and $3 \mathrm{wt} \% \mathrm{GO} / \mathrm{Nafion}$ membrane was comparable with that of recast Nafion. This is due to the composite membrane's extremely low electrical conductivity and slightly higher proton conductivity than Nafion as shown in Table I. The low electrical conductivity is due to the low loading of GO in the membranes, whereas the improved proton conductivity is due to the high amounts of oxygen functional groups in $\mathrm{GO}^{20}$ When the GO loading was increased to $5 \mathrm{wt} \%$, the membrane's electrical conductivity was greatly increased, reducing its fuel cell performance. It could be due to the formation of electron transport pathways by forming aggregates.

Table I. Proton conductivity and electrical conductivity of recast Nafion and GO/Nafion membranes.

\begin{tabular}{ccc} 
Membrane & $\begin{array}{c}\text { Proton } \\
\text { conductivity } \\
(\mathrm{mS} / \mathrm{cm})\end{array}$ & $\begin{array}{c}\text { Electrical } \\
\text { conductivity } \\
(\mathrm{S} / \mathrm{m})\end{array}$ \\
\hline Recast Nafion & 77.42 & 0.0024 \\
2.3wt\% Graphene Oxide/Nafion & 80.40 & 0.0034 \\
3wt\% Graphene Oxide/Nafion & 83.80 & 0.0041 \\
5wt\% Graphene Oxide/Nafion & 91.93 & 0.1897
\end{tabular}




\section{Conclusions}

Graphene oxides were incorporated into Nafion polymer membranes to provide mechanical reinforcement while preserving the membrane's low electronic conductivity due to the GO's nonconductive property. TEM images showed that the highly crystalline GO sheets were individually dispersed. Tensile tests confirmed that the addition of GO greatly improved the tensile strength of the composite membrane. Water uptake and swelling measurements showed that the addition of GO also dramatically improved the composite membranes' dimensional stability. The improved tensile strength and dimensional stability by adding graphene oxide can enhance the robustness and integrity of the constrained MEAs within the assembled fuel cell and improve its durability. The fuel cell performance of the $3 \mathrm{wt} \% \mathrm{GO} /$ Nafion membranes showed similar fuel cell performance with recast Nafion, but with improved mechanical properties. This indicates that graphene oxide is a viable material for the production of reinforced Nafion membranes for fuel cell applications.

\section{Acknowledgment}

This work was conducted under the University of Delaware's Fuel Cell Bus Program to research, build, and demonstrate fuel cell powered hybrid vehicles for transit applications. This program is funded by the Federal Transit Administration at the Center for Fuel Cell Research at the University of Delaware. This work was supported by the National Research Foundation of Korea (NRF) grant funded by the Korean government (MSIP) (2009-0083540, NRF2014R1A2A2A01005496). We thank Y.C. Kim for preparing the GO sample.

\section{References}

1. U. S. Department of Energy, http://energy.gov/eere/fuelcells/fuel-cells.

2. R. Borup, Chemical Reviews, 107, 3904 (2007).

3. S. C. Yeo and A. Eisenberg, Journal of Applied Polymer Science, 21(4), 875 (1977).

4. T. E. Springer, T. A. Zawodzinski, and S. Gottesfeld, Journal of the Electrochemical Society, 138(8), 2334 (1991).

5. Y. Kawano, Y. Q. Wang, R. A. Palmer, and S. R. Aubuchon, Polimeros: Ciencia e Technologia, 12(2), 96 (2002).

6. L. C. Chena, T. L. Yu, H. L. Lin, and S. H. Yeh, J .Membrane Science, 307, 10 (2007).

7. R. R. Schlittler, J. W. Seo, J. K. Gimzewski, C. Durkan, M. S. M. Saifullah, and M. E. Welland, Science, 292, 1136 (2001).

8. C. Richard, F. Balavoine, P. Schultz, T. W. Ebbesen, and C. Mioskowski, Science, 300, 775 (2003).

9. M. P. S. Shaffer and A. Windle, Advanced Materials, 11, 937 (1999).

10. D. R. Dreyer, S. Park, C. W. Bielawski, and R. S. Ruoff, Chemical Society Reviews, 39, 228 (2010).

11. J. Kim, L. J. Cote, and J. Huang, Accounts of Chemical Research, 45, 1356 (2012).

12. D. Chen, H. Feng, and J. Li, Chemical Reviews, 112, 6027 (2012).

13. B. G. Choi, Y. S. Huh, Y. C. Park, D. H. Jung, W. H. Hong, and H. Park, Carbon, 50, 5395 (2012).

14. A. Enotiadis, K. Angjeli, N. Baldino, I. Nicotera, and D. Gournis, Small, 8(21), 3338 (2012).

15. W. S. Hummers and R. E. Offeman, Journal of the American Chemical Society, 80, 1339 (1958)

16. S. Stankovich, R. D. Piner, S. T. Nguyen, and R. S. Ruoff, Carbon, 44, 3342 (2006).

17. ASTM Standard D882-02, Standard Test Method for Tensile Properties of Thin Plastic Sheeting.

18. D. W. Boukhvalov and M. I. Kastsnelson, Journal of the American Chemical Society, 130, 10697 (2008)

19. A. C. Ferrari, Physical Review Letters, 97, 187401 (2006).

20. A. K. Mishra, N. H. Kim, D. Jung, and J. H. Lee, Journal of Membrane Science, 458, 128 (2014). 